\title{
Reduction of Worker Exposure to Solvents by Means of an Occupational Health Program: An Experience at a Synthetic Leather Factory in Taiwan
}

\author{
Hsien-Wen Kuo ${ }^{1 *}$, K. C. Lin ${ }^{1}$, Y. S. Huang ${ }^{1}$, J. C. Lou ${ }^{2}$, \\ T. J. $\mathrm{CHENG}^{3}$ and M. J. Chang $\mathrm{Wu}^{2}$ \\ 'Institute of Environmental Health, China Medical College, \\ ${ }^{2}$ College of Medicine, Chang Gung University, \\ ${ }^{3}$ Graduate Institute of Occupational Medicine and Industrial Hygiene, National Taiwan University
}

\begin{abstract}
Reduction of Worker Exposure to Solvents by means of an Occupational Health Program: An Experience at a Synthetic Leather Factory in Taiwan: Hsien-Wen Kuo, et al. Institute of Environmental Health, China Medical CollegeObjective-To assess the effects of an occupational health program which was to reduce synthetic leather workers' exposure to solvents ( $\mathrm{N}, \mathrm{N}$-dimethylformamide (DMF), epichlorohydrin ( $\mathrm{ECH}$ ) and toluene). Methods-Worker exposure to these airborne solvents was measured in 1999 and compared with results obtained in 1997. Due to high solvent levels in the workplace, an occupational health program was implemented in 1997 to reduce worker exposure to solvents. Biological monitoring was conducted by measuring workers' urinary DMF, NMF (Nmethylformamide) and formamide concentrations, and the factors influencing these indicators were investigated. NMF levels obtained in 1997 were compared with levels in 1999. Results-Airborne DMF, $\mathrm{ECH}$ and toluene concentrations were significantly reduced in all three workstations in the 1999 study (compared to the 1997 study). In 1997, the urinary NMF concentration was $3.31 \mathrm{mg} / \mathrm{g}$ cre. compared to $2.13 \mathrm{mg} / \mathrm{g}$ cre. in 1999 , which represented a $35.6 \%$ decrease. Urinary DMF and formamide concentrations were 0.42 and $1.24 \mathrm{mg} / \mathrm{g}$ cre., respectively, in 1999. There was a positive correlation between urinary NMF concentration and environmental DMF $(r=0.49$ for area sampling, $r=0.55$ for personal sampling). For biological monitoring, the urinary NMF concentration was significantly correlated with formamide $(r=0.79)$ and parent DMF $(r=0.33)$. Multiple regressions showed that
\end{abstract}

Received March 26, 2001; Accepted Aug 11, 2001 Correspondence to: H. W. Kuo, Institute of Environmental Health, China Medical College, No 91, Hsueh-Shin RD., Taichung, Taiwan, R.O.C. the factors affecting the concentration of the biological indicators (NMF, DMF and formamide) in urine were: airborne DMF concentration, duration of worker employment and alcohol consumption. ConclusionThe occupational health program implemented in 1997 was effective in quickly reducing airborne solvents, but urinary NMF levels were not as responsive.

(J Occup Health 2001; 43: 339-345)

Key words: Occupational health program, DMF, NMF, Biological monitoring

In 1997 the authors monitored worker exposure to solvents in a polyurethane factory in Taiwan. The study found that one fifth of the workers had liver enzyme abnormalities (ALT (aspartate aminotransferase) levels were high). In Taiwan, permissible levels of DMF (N,NDimethylformamide) and ECH (Epichlorohydrin) are 10 ppm and $2 \mathrm{ppm}$, respectively. Of 41 area samples, 15 (36.6\%) and $5(12.2 \%)$ exceeded permissible exposure levels for DMF and $\mathrm{ECH}$, respectively, compared to the 77 personal samples: $22(28.6 \%)$ and $3(3.9 \%)$. For area samples, DMF and ECH concentrations were $78.6 \pm 32.2$ ppm and $23.4 \pm 6.2 \mathrm{ppm}$. For personal samplers, DMF and $\mathrm{ECH}$ concentrations were $95.8 \pm 30.2 \mathrm{ppm}$ and $8.4 \pm$ $10.5 \mathrm{ppm}^{1)}$, and blood samples from these workers showed a higher frequency of sister chromatid exchange, indicating that $\mathrm{ECH}$ exposure may be associated with genetic toxicity, but DMF did not appear to be genotoxic ${ }^{2)}$. Angerer (1998) reported that DMF leads to Nmethylcarbamoylated adducts at the $\mathrm{N}$-terminal valine of the hemoglobin, detected by capillary gas chromatography and mass selective detector (GC-MS). This finding suggests that DMF exposure could have a genotoxic effect ${ }^{3)}$. The authors (Luo, 2001) assessed the liver function of workers exposed to DMF in the same 
factory as used in the current study. The prevalence of abnormal liver enzyme was measured: AST (alanine amino-transferase) was $10.8 \%$, ALT was $20.5 \%$ and $\gamma$ GT (gamma-glutamyl transpeptidase) was $9.7 \%$. These results demonstrated a significant dose-response relationship between liver enzyme abnormalities and DMF exposure among workers. The high incidence of liver abnormalities among the workers and the high level of airborne solvent concentrations in specific areas of the plant were of concern to the plant managers and workers. Industrial hygienists developed an occupational health program to measure worker exposure to solvents every six months by assessing urinary NMF and airborne DMF. In order to maximize the effectiveness of the occupational health program, the efforts of industrial hygienists, plant managers and medical workers were closely coordinated. The data on airborne DMF, ECH and toluene levels from the original study in 1997 were compared to data collected in 1999. In addition, in the 1999 study parent DMF, formamide and NMF concentrations were measured, but only the latter compound was measured in the 1997 study. The objective of the current study was to evaluate the effects of an occupational health program for reducing synthetic leather workers' exposure to DMF, ECH and toluene. Workers' urinary DMF, NMF and formamide concentrations were also measured and the factors that affected these biological indicators were investigated.

\section{Methods}

Thirty-seven subjects ( 34 male, 3 female) were selected from the three workstations. Please refer to the 1997 study for details of the areas that comprised the three workstations ${ }^{1 !}$. Prior to the first visit in 1997, preliminary sampling indicated that in workstation I there were high concentrations of DMF and toluene. In workstation II DMF concentrations were moderate and toluene concentrations were low. In workstation III, DMF concentrations were low but ECH levels were high. A questionnaire was used to collect subjects' demographic data: the average age was thirty-five, $4 \%$ of subjects had a work duration of 6-10 yr, 98\% had an education level of at least high school, and $78 \%$ were married. Information about workers' personal protective equipment (PPE) and medical problems (respiratory, musculoskeletal and psychological) in the three months prior to the commencement of the study were obtained. Over $70 \%$ of workers used PPE, which included a helmet, gloves, safety shoes and respiratory mask. Only $30 \%$ of workers wore protective clothes and earmuffs.

\section{Occupational health program:}

The plant management, in consultation with the authors (1997 study), implemented an occupational health program, which included the following: (1) Improved localized ventilation and separation of areas within each of the workstations, (especially in the high DMF exposure areas of the plant). (2) Provision of operation manuals for workers to improve safety awareness and decrease inefficient operation of the machines, which could lead to greater evaporation of solvents. (3) Recycling equipment was installed to recycle DMF waste from the PU (polyurethane) coating machine and wash shower (192.5 tons/month recovered), which was previously discarded. (4) Workers were required to wear PPE, including a respiratory mask (containing active charcoal). (5) Workers' shifts were rotated to reduce work duration in high exposure areas. (6) A program of six-monthly monitoring of the DMF concentration by a certified industrial hygienist was implemented. If solvent concentrations exceeded permissible limits after the occupational hygiene program was implemented then the control devices were adjusted accordingly. (7) Blood samples from workers with liver abnormalities were monitored annually. Work shifts were also rotated to reduce work duration in areas with high solvent levels.

\section{Environmental monitoring:}

The environmental monitoring conducted in this study was almost identical to that of the 1997 study"). Both area and personal sampling tasks were performed. A total of 28 area samplings were selected throughout the plant. Sampling time ranged from 60 to $180 \mathrm{~min}$. Thirty-seven workers from the three workstations were selected for personal sampling. These workers were the same as those who participated in the 1997 study. A sampler was attached to the workers' shirt collars. For personal samples, all calculations were based on the time-weight average (TWA). Analysis was completed within one week of sampling. Charcoal was desorbed with $\mathrm{CS}_{2}$ and acetone (3:2 proportion by volume). An internal standard, $\mathrm{Xylene}$, was then added to the desorbed solution. Analysis of the solvents was performed by GC/FID (HP6890 series II) with a fused silica WCOT column (DB5-30 $\mathrm{m} \times 0.53 \mathrm{~mm}$ ID). Quality control for the calibration curve was performed by calculating the correlation coefficient $(>0.999)$ and the relative prediction deviation $(<5 \%)$. The reproducibility $(\mathrm{CV})$ of the three solvents (at low and high concentrations) ranged from $0.1 \%$ to $3.1 \%$. Average desorption efficiencies were triplicated for DMF (0.42 TLV, $1.05 \mathrm{TLV}, 2 \mathrm{TLV})$ and ECH $\left(0.53 \mathrm{TLV}, 1.15 \mathrm{TLV}, 2.02 \mathrm{TLV}^{5)}\right.$ and were found to be $104.5 \%$ and $102.7 \%$, respectively. Detection limits ( $1 \mu l$ was injected) for airborne $\mathrm{DMF}, \mathrm{ECH}$, and toluene were $2.0 \mathrm{ng}, 0.3 \mathrm{ng}$, and $0.41 \mathrm{ng}$, respectively.

\section{Biological monitoring:}

Urine samples from all 37 subjects were taken after the work shift. Urinary NMF as well as parent DMF and formamide levels were assessed. Pretreatment was the 
Table 1. Comparison of DMF, ECH and Toluene concentrations $\left(\mathrm{mg} / \mathrm{m}^{3}\right)$ in 1997 and 1999 from personal and area sampling at three workstations

\begin{tabular}{|c|c|c|c|c|c|c|c|c|}
\hline & \multirow[b]{2}{*}{$\mathbf{n}$} & \multicolumn{3}{|c|}{1997} & \multirow[b]{2}{*}{$\mathrm{n}$} & \multicolumn{3}{|c|}{1999} \\
\hline & & $\mathrm{DMF}$ & $\mathrm{ECH}$ & Toluene & & DMF & $\mathrm{ECH}$ & Toluene \\
\hline Personal sampling & & & $\mathrm{N}=77$ & & & & $\mathrm{~N}=37$ & \\
\hline Workstation I & 22 & $\begin{array}{c}270.4 \pm 75.2^{*} \\
(\mathrm{ND}-360.4)\end{array}$ & ND & $\begin{array}{l}100.0 \pm 38.6 \\
(\mathrm{ND}-333.3)\end{array}$ & 10 & $\begin{array}{c}4.33 \pm 3.34 \\
(0.9-10.3)\end{array}$ & ND & $\begin{array}{l}24.58 \pm 33.3 \\
(3.46-115.5)\end{array}$ \\
\hline Workstation II & 27 & $\begin{array}{l}42.0 \pm 18.2 \\
(\mathrm{ND}-940.6)\end{array}$ & ND & $\begin{array}{l}4.0 \pm 2.2 \\
(\mathrm{ND}-9.9)\end{array}$ & 11 & $\begin{array}{l}2.12 \pm 1.73 \\
(\mathrm{ND}-0.30)\end{array}$ & ND & $\begin{array}{l}8.01 \pm 8.73 \\
(0.15-30.9)\end{array}$ \\
\hline Workstation III & 28 & $\begin{array}{l}10.7 \pm 6.8 \\
(\mathrm{ND} 41.0)\end{array}$ & $\begin{array}{c}8.4 \pm 10.5 \\
(\mathrm{ND}-63.0)\end{array}$ & $\begin{array}{c}5.9 \pm 4.5 \\
(\mathrm{ND}-19.4)\end{array}$ & 16 & $\begin{array}{l}0.17 \pm 0.20 \\
(\mathrm{ND}-0.51)\end{array}$ & $\begin{array}{l}0.18 \pm 0.20 \\
(\mathrm{ND}-0.46)\end{array}$ & $\begin{array}{l}2.79 \pm 7.33 \\
(\mathrm{ND}-3.03)\end{array}$ \\
\hline Area sampling & & & $\mathrm{N}=41$ & & & & $\mathrm{~N}=28$ & \\
\hline Workstation I & 21 & $\begin{array}{l}118.4 \pm 56.2 \\
(\mathrm{ND}-583.0)\end{array}$ & ND & $\begin{array}{l}23.3 \pm 11.5 \\
(\mathrm{ND}-100.2)\end{array}$ & 10 & $\begin{array}{c}5.76 \pm 5.5 \\
(0.22-16.7)\end{array}$ & ND & $\begin{array}{c}11.80 \pm 50.6 \\
(1.18-28.1)\end{array}$ \\
\hline Workstation II & 9 & $\begin{array}{l}51.1 \pm 10.3 \\
(0.6-264.4)\end{array}$ & ND & $\begin{array}{c}3.0 \pm 1.4 \\
(1.07-12.9)\end{array}$ & 14 & $\begin{array}{l}3.50 \pm 3.21 \\
(1.04-11.7)\end{array}$ & ND & $\begin{array}{l}3.31 \pm 2.37 \\
(0.82-6.68)\end{array}$ \\
\hline Workstation III & 11 & $\begin{array}{l}25.0 \pm 4.5 \\
(1.2-92.5)\end{array}$ & $\begin{array}{c}23.4 \pm 6.2 \\
(0.5-131.5)\end{array}$ & $\begin{array}{c}30.7 \pm 6.2 \\
(2.0-109.9)\end{array}$ & 4 & $\begin{array}{l}0.27 \pm 0.08 \\
(0.17-0.35)\end{array}$ & $\begin{array}{c}0.39 \pm 0.21 \\
(0.20-0.67)\end{array}$ & $\begin{array}{l}0.30 \pm 0.16 \\
(0.12-0.48)\end{array}$ \\
\hline
\end{tabular}

ND: non-detectable. *Mean \pm SD (range). **Non-parametric test to show significant differences between the 1997 and 1999 studies in solvent concentrations.

same as in the 1997 study $^{1,6)}$; centrifugation was set at $10,000 \times \mathrm{g}$ for $20 \mathrm{~min}$ and the urine supernatant was extracted. An internal standard ( $\mathrm{N}$-methylacetamide) was added to the samples and standard before centrifugation at $10,000 \times \mathrm{g}$ for $10 \mathrm{~min}$. The supernatant was collected and analyzed with GC-NPD (HP 6890 series II) fused silica WCOT (DB WAX $30 \mathrm{~m} \times 0.25 \mathrm{~mm}$ ID). Calibration curves for DMF, NMF and formamide were used to calculate the correlation coefficents (all were $>0.999$ ). Two levels (0.66 $\mathrm{mg}$ and $0.42 \mathrm{mg}$ ) of NMF, DMF and formamide were spiked on the urine samples and the recovery rates were as follows: $106.4 \%, 94.7 \%$ and $102.4 \%$, respectively. Stability (mean recovery efficiency) at $4^{\circ} \mathrm{C}$ on days $0,1,4$ and 7 for DMF, NMF and formamide was $105.8 \%, 105.7 \%$ and $102.9 \%$, respectively. With an injection volume of $1 \mu l$, the detection limits for DMF, NMF and formamide were found to be $0.025 \mathrm{ng}, 0.023 \mathrm{ng}$ and $0.103 \mathrm{ng}$, respectively.

Statistical Analysis: An SAS/PC 6.04 package $^{7)}$ was used to analyze the results. A non-parametric test was used to compare the DMF, ECH and toluene concentrations in the two studies (1997 and 1999). Pearson's correlation was used to show the correlation between environmental and biological monitoring. Multiple regression models were used to determine the factors that affected the concentrations of the biological indicators.

\section{Results}

Table 1 compares personal and area sampling concentrations of DMF, ECH and toluene in 1997 and 1999. The concentrations of all three solvents declined sharply overall in 1999, particularly for DMF, in all three stations. For area sampling in workstation I (1997), DMF and toluene concentrations were $118 \mathrm{mg} / \mathrm{m}^{3}$ and $23.3 \mathrm{mg} /$ $\mathrm{m}^{3}$ compared to $5.76 \mathrm{mg} / \mathrm{m}^{3}$ (a $80.2 \%$ decrease) and 11.80 $\mathrm{mg} / \mathrm{m}^{3}$ (a $49.4 \%$ decrease) in 1999 . The decrease in area sampling data (from 1997 to 1999) was smaller than that in personal sampling. For area sampling, ECH concentration in workstation III decreased from $23.4 \mathrm{mg} /$ $\mathrm{m}^{3}$ in 1997 to $0.39 \mathrm{mg} / \mathrm{m}^{3}$ (a $98.3 \%$ decrease) in 1999 , but for personal sampling, the ECH concentration in workstation III decreased from $8.4 \mathrm{mg} / \mathrm{m}^{3}$ in 1997 to 0.18 $\mathrm{mg} / \mathrm{m}^{3}$ (a $97.9 \%$ decrease) in 1999. For workstations I and II, in both periods, ECH was not detected. In 1997, $28.6 \%$ and $3.9 \%$ of personal samples, and $36.6 \%$ and $12.2 \%$ of area samples for DMF and ECH exceeded the limit, but in 1999, none of the solvents exceeded permissible limits in Taiwan ${ }^{8}$.

In Table 2 it can be seen that the mean concentration of urinary NMF decreased from $3.31 \mathrm{mg} / \mathrm{g}$ cre. in 1997 to $2.13 \mathrm{mg} / \mathrm{g}$ cre. in 1999 (a $35.6 \%$ decrease). Urinary DMF and formamide concentrations were measured in 1999 (but not in 1997) and were found to be $0.42 \mathrm{mg} / \mathrm{g}$ cre. and $1.24 \mathrm{mg} / \mathrm{g}$ cre., respectively. Urinary NMF and formamide concentrations in 1999 were 5.07 times and 
2.95 times higher, respectively, than urinary parent DMF concentrations.

Table 3 shows the correlation between the environmental and biological monitoring for DMF. There was a high correlation between area and personal sampling $(r=0.71)$. There was a significant correlation between the urinary NMF concentration and both personal and area sampling ( $r=0.55$ and $r=0.49$, respectively). The urinary parent DMF concentration correlated significantly with area sampling $(\mathrm{r}=0.39)$ and there was a significant correlation between the urinary formamide concentration and personal sampling $(\mathrm{r}=0.38)$. Urinary NMF correlated (significantly) more closely with urinary formamide $(\mathrm{r}=0.79)$ than with parent DMF $(r=0.33)$.

Table 2. Comparison of urinary DMF metabolite concentrations (mg/g cre.) in 1997 and 1999

\begin{tabular}{lcc}
\hline & 1997 & 1999 \\
\cline { 3 - 3 } Parent DMF & NA & $0.42 \pm 0.11$ \\
NMF & $3.31 \pm 1.20$ & $2.13 \pm 0.94$ \\
Formamide & NA & $1.24 \pm 0.80$ \\
\hline
\end{tabular}

NA: Non-available.
Table 4 shows the factors that affect the concentration of biological monitors for DMF exposure when using multiple regression models. Because age (in years) and work duration were closely correlated, only the latter factor was used. And because there were only three female subjects, gender was not included as a variable. The variables were as follows: airborne DMF concentration (personal sampling), work duration, alcohol and tobacco consumption, and the use of PPE. There was a significant positive correlation between the urinary NMF concentration and work duration $(p<0.05)$. The $\mathrm{NMF}$ concentration increased $0.34 \mathrm{mg} / \mathrm{g}$ cre. for each year of work duration. The airborne DMF concentration correlated positively with the urinary NMF concentration, but this was not significant. There was no correlation between the urinary NMF concentration and alcohol and tobacco consumption. There were no predicting variables for the urinary parent DMF concentration. The urinary formamide concentration was positively correlated with the airborne DMF concentration (the formamide concentration increased $0.65 \mathrm{mg} / \mathrm{g}$ cre. for every $\mathrm{mg} / \mathrm{m}^{3}$ of DMF (personal sampling)). The urinary formamide concentration also correlated positively with alcohol consumption. The mean urinary formamide concentration among workers who consumed alcohol was $2.69 \mathrm{mg} / \mathrm{g}$ cre. higher than among non-drinkers, but there was no

Table 3. Correlation between environmental and biological monitoring of DMF

\begin{tabular}{|c|c|c|c|c|c|}
\hline & \multirow{2}{*}{$\begin{array}{c}\text { Area } \\
\text { sampling }\end{array}$} & \multirow{2}{*}{$\begin{array}{l}\text { Personal } \\
\text { sampling }\end{array}$} & \multicolumn{3}{|c|}{ Biological monitoring } \\
\hline & & & Parent DMF & NMF & Formamide \\
\hline Area sampling & 1 & & & & \\
\hline Personal sampling & $0.71^{* *}$ & 1 & & & \\
\hline \multicolumn{6}{|c|}{ Biological monitoring } \\
\hline Parent DMF & $0.39 *$ & 0.15 & 1 & & \\
\hline NMF & $0.49 * *$ & $0.55^{* * *}$ & 0.33 & 1 & \\
\hline Formamide & 0.29 & $0.38 *$ & $0.35 *$ & $0.79^{* *}$ & 1 \\
\hline
\end{tabular}

$* P<0.05, * * P<0.01$.

Table 4. Factors that affect the concentration of the urinary DMF metabolites using multiple regression

\begin{tabular}{|c|c|c|c|c|}
\hline & $\begin{array}{l}\mathrm{NMF} \\
\beta(\mathrm{SE})\end{array}$ & $\begin{array}{l}\text { Parent DMF } \\
\beta(\mathrm{SE})\end{array}$ & $\begin{array}{c}\text { Formamide } \\
\beta(\mathrm{SE})\end{array}$ & $\begin{array}{c}\text { Total metabolites } \\
\beta(\mathrm{SE})\end{array}$ \\
\hline Personal sampling $\left(\mathrm{mg} / \mathrm{m}^{3}\right)$ & $0.49 \quad(0.35)$ & $0.01 \quad(0.04)$ & $0.65^{*}(0.23)$ & $1.17 * *(0.53)$ \\
\hline Work duration (yr) & $0.34 *(0.16)$ & $0.004(0.002)$ & $0.07 \quad(0.1)$ & $0.42 *(0.22)$ \\
\hline Alcohol consumption (no $=0$ ) & $2.22 \quad(1.83)$ & $0.28 \quad(0.22)$ & $2.69 *(1.23)$ & $4.16 \quad(2.75)$ \\
\hline Smoking $(\mathrm{no}=0)$ & $1.56 \quad(1.81)$ & $0.27 \quad(0.21)$ & $0.89 \quad(1.21)$ & $2.08 \quad(2.63)$ \\
\hline Respirator $(\mathrm{no}=0)$ & $-0.44 \quad(0.27)$ & $-0.04 \quad(0.03)$ & $0.15 \quad(0.18)$ & $-0.22 \quad(0.39)$ \\
\hline Glove use $($ no $=0)$ & $-0.17 \quad(0.12)$ & $-0.001(0.02)$ & $0.13(0.11)$ & $-0.62 *(0.28)$ \\
\hline
\end{tabular}

${ }^{*} P<0.05,{ }^{* *} P<0.01$. Total metabolites $=$ parent $\mathrm{DMF}+\mathrm{NNF}+$ Formamide. ${ }^{a}$ "no' indicates the baseline which is zero to compare to 'yes' which is equal to 1 . 
correlation with smoking. When the three biological monitors for DMF were totaled (additive total of NMF, parent DMF and formamide concentrations), there was a significant positive correlation with the airborne DMF concentration. The total metabolite concentration increased $1.17 \mathrm{mg} / \mathrm{g}$ cre. for every $\mathrm{mg} / \mathrm{m}^{3}$ of DMF exposure (personal sampling). Work duration and alcohol consumption also correlated positively with total metabolites, but only the former factor was significant. The total metabolite concentration increased $0.42 \mathrm{mg} / \mathrm{g}$ cre. for every year of work. If workers wore gloves as part of PPE, the total metabolite concentration was 0.62 $\mathrm{mg} / \mathrm{g}$ cre. lower than for workers who did not wear gloves.

\section{Discussion}

The authors' 1997 study showed that one fifth of the workers had liver dysfunction and this correlated significantly with DMF exposure (personal sampling). Wang (1991) reported that there was an interactive (synergistic) effect between workers who were $\mathrm{HBsAg}$ carriers and also exposed to $\mathrm{DMF}^{8)}$. Luo (2000) investigated the same plant as the current study and obtained similar results to Wang's study ${ }^{41}$. The problem of worker exposure to DMF may be exacerbated in Taiwan since $15-20 \%$ of Taiwan's population are HBsAg carriers ${ }^{9 j}$. Due to the number of workers with liver dysfunction and the high solvent concentrations in some areas of the plant, plant managers asked an industrial hygienist to cooperate with medical staff, engineers and academic experts to design an occupational health program. The most effective procedure of the program was the improvement of the local ventilation system and separation of areas within each of the workstations. In order to assess the efficacy of the program implemented in 1997, worker exposure to solvents was periodically evaluated by measuring urinary NMF and airborne DMF. Results showed that there had been a sharp decline in concentrations of DMF, ECH and toluene in both personal and area sampling since 1997. DMF and ECH concentrations both decreased overall by about $95 \%$. The authors suggest that the decrease in the airborne solvent concentration was due, in part, to the control devices and occupational hygiene program that were implemented in 1997. In addition, there was a $35 \%$ decrease in the frequency of nausea, fatigue and headache reported by workers. In 1997, one fifth of the workers were diagnosed as having a liver problem (ALT>35), but in 1999 there were much fewer symptoms of liver problems among these workers, but for specific liver function tests there were no available data. This may be the subject of further research by the authors. The plant will be periodically monitored to measure the continuing effects of the occupational health program. The health status of the workers will also be continually assessed. It is important to note that the total amount of DMF used in the plant decreased, from 1473.4 tons/month in 1997 to 875 tons/month in 1999.
Polyurethane production decreased from 4.2 million yards in 1997 to 1.81 million yards in 1999 . The decrease by $57 \%$ from 1997 to 1999 in production of polyurethane and the decrease in the use of DMF by $40 \%$ certainly contributed to the reduction in airborne solvents but the role of the occupational health program also had an impact since the decrease in airborne solvent concentrations was considerable (over $90 \%$ for DMF and ECH). The authors suggest that the experience of the current study may be used as a reference by plants and academic institutions. Plant workers are becoming increasingly concerned about the effect on health of long-term exposure to solvents in the workplace. In turn, plant managers are becoming increasingly aware of how poor worker health may negatively affect the public's perception of the manufacturer. We suggest that plant managers, engineers, academic experts and physicians cooperate to reduce worker exposure to solvents, by implementing an occupational hygiene program.

Mraz (1989) said that five urinary indicators for worker exposure to DMF may be used: parent DMF, NMF, DMF$\mathrm{OH}$, formamide and AMCC. Determination of urinary levels of NMF is routinely used for biological monitoring of occupational exposure to DMF in many countries ${ }^{10 !}$. The half-life of NMF is short and can only accurately represent short-term exposure (relative to the accuracy of AMCC) to DMF. AMCC has a longer half-life and can better represent long-term exposure to $\mathrm{DMF}^{11,12)}$. AMCC is more reliable than NMF for measuring longterm exposure to DMF, but this marker was not used since there were no commercially available standard tests for analysis of urinary AMCC. There are also no documented standards (Biological Exposure Indices (BEI)) for AMCC. In the current study, despite a significant decrease in environmental monitors from 1997 to 1999 , there was a somewhat significant decrease in urinary NMF $(3.31 \mathrm{mg} /$ g cre. in $1997 ; 2.13 \mathrm{mg} / \mathrm{g}$ cre. in 1999). The authors speculate that the levels of NMF at the time of the first visit may have been underestimated since airborne DMF was so high. Sakai has suggested that the body's total production of the enzymes responsible for detoxification of DMF may already have reached maximum levels, therefore it may have taken a long time for urinary NMF to decrease. Workers who wore PPE, including a respiratory mask may still have been exposed to airborne DMF by dermal contact ${ }^{13)}$. It may be necessary to review the use of gloves and their proper usage with a view to replacing them in this plant. Wearing PPE may explain the difference between the results of the current study and those reported by Wribitzky and Angerer (1996) with regard to the intake and exposure dose of $\mathrm{DMF}^{14}$. Further research needs to be done to evaluate the extent to which dermal absorption contributes to total DMF absorption. Because of the high degree of variation in the results of the 1997 study, and the short half-life of NMF, it is 
possible that NMF levels were underestimated.

Kawai (1992) reported that there was a linear relationship between $D M F$ in air and $N$ monomethylformamide (MMF) in urine, and estimated that about $10 \%$ of the DMF absorbed was excreted into the urine as MMF precursors ${ }^{15}$. Kimmerle and Eben (1975) reported that there was a significant correlation between airborne DMF and urinary parent DMF. Of the airborne DMF, only $0.5 \%$ was obtained in the urinary parent form ${ }^{16)}$. Mraz (1989) reported that formamide is the last compound in the metabolic pathway of DMF and comprises $13 \%$ of the original DMF. Urinary formamide concentrations are usually highest $4-20 \mathrm{~h}$ after the end of the work shift ${ }^{9}$. In the 1997 study, parent DMF and formamide concentrations were not measured. During the first visit, the objective of the study was to investigate the relationship between DMF and NMF and to ascertain whether they exceeded permissible limits. At the time of the second visit, in addition to monitoring DMF and NMF levels, the authors were interested in investigating the correlation between parent DMF, formamide and NMF. In 1999, the concentrations of parent DMF and formamide were $0.42 \mathrm{mg} / \mathrm{g}$ cre. and $1.24 \mathrm{mg} / \mathrm{g}$ cre., respectively. Urinary NMF and formamide concentrations were 5.08 times and 2.95 times greater, respectively, than urinary parent DMF. Area and personal sampling for DMF positively correlated with urinary NMF. This was consistent with the results by Yonemoto et $a l^{(7)}$. The correlation between airborne DMF and urinary NMF was higher than the correlation between airborne DMF and both urinary parent DMF and urinary formamide. These findings demonstrate that urinary NMF is a suitable marker for exposure to airborne DMF. Mraz and Nahova (1992) reported that dermal absorption of DMF might represent $13-36 \%$ of total uptake ${ }^{18)}$. In 1999 , solvent workers were required to wear PPE, thereby reducing dermal absorption of DMF. This may explain the increase in the correlation of personal sampling of DMF with urinary NMF from 1997 ( $\mathrm{r}=0.31$ ) to 1999 (r=0.55). This finding may be explained by Wrbitzky and Angerer (1998) who found a positive, but weak, association between the airborne DMF concentration and values recorded for internal exposure to $\mathrm{DMF}^{(9)}$.

In conclusion, professionals from different fields cooperated to develop an occupational health program which significantly reduced airborne solvent concentrations in the workplace. Airborne DMF and ECH levels decreased by about $90 \%$ from 1997 to 1999 , but there was only a slight decrease in urinary NMF concentration. The reasons for this require further research. Environmental DMF correlated positively with urinary NMF, parent DMF and formamide concentrations. The occupational health program implemented in 1997 was effective in quickly reducing airborne solvents, but urinary NMF levels were not as responsive. This study may be used as a reference for researchers and plant managers to reduce worker exposure to solvents.

\section{References}

1) Kuo HW, Huang YU, Chang MJW, Luo JC, Cheng TJ. Assessment of solvent hazards in a synthetic leather manufacturing plant. Int Occup Environ Health 2000; 73: 275-280.

2) Cheng TJ, Hwang SJ, Kuo HW, Luo JC, Chang Wu MJ. Exposure to epichlorohydrin and dimethylformamide, gluthathione S-transferases and sister chromatid exchange frequencies in peripheral lymphocytes. Arch Toxicol 1999; 73: 282-287.

3) Angerer J, Gaen T, Kramer A, Kafferlein HU. Nmethylcarbamoyl adducts at the $\mathrm{N}$-terminal valine of globin in workers exposure to N,Ndimethylformamide. Arch Toxicol 1998; 72: 309-312.

4) Luo JC, Kuo HW, Cheng TJ, Chang MJW. Abnormal liver function associated with occupational exposure to dimethylformamide and hepatitis B virus. JOEM $2001 ; 43: 474-482$.

5) American Conference of Governmental Industrial Hygienists (ACGIH). Threshold limit values and biological exposure induces. ACGIH, 1999.

6) Lareo AC, Perico A, Bavazzano P, Soave C, Perbellini L. Biological monitoring of workers exposed to N,Ndimethylformamide. I methods of analysis. Int Arch Occup Environ Health 1995; 67: 41-46.

7) SAS/STAT User's guide, release 6.12. SAS, Cary, N.C., 1992.

8) Wang JD, Lai JD, Chen JS, Lin JM. Dimethylformamide-induced liver damage among synthetic leather workers. Arch Environ Health 1991; 46: 161-166.

9) Taiwan Department of Health Public Health Annual Report, Republic of China, Taiwan. 2000.

10) Mra $J$, Cross H, Gescher A, Threadgill MD, Flek J. Difference between rodents and humans in the metabolic toxification of N,N-Dimethylformamide. Toxiol Appl Pharm 1989; 98: 507-516.

11) Sakai K, Kageyama H, Araki A, Yosida T, Kuribayashi I, Masuyama Y. Biological monitoring of workers exposed $\mathrm{N}, \mathrm{N}$-dimethylformamide by determination of the urinary metabolites, $\mathrm{N}$-methylformamide and $\mathrm{N}$ acetyl-S-(N-methylcarbamoyl) cysteine. Int Arch Occup Environ Health 1995; 67: 125-129.

12) Kafferlein HU, Goen T, Muller J, Wrbitzky R, Angerer J. Biological monitoring of workers exposed to N,Ndimethylformamide in the synthetic fiber industry. Int Arch Occup Environ Health 2000; 73: 113-120.

13) Yang JS, Kim EA, Lee MY, Park IJ, Kang SK. Biological monitoring of occupation exposure to $\mathrm{N}, \mathrm{N}$ dimethylformamide-the effects of co-exposure to toluene or dermal exposure. Int Arch Occup Environ Health 2000; 73: 463-470.

14) Wrbitzky R, Angerer J, Lehnert G. External and internal monitoring in workers exposure to N,Ndimethylformamide. Int Arch Occup Environ Health 1996; 68: 508-510.

15) Kawai T, Yasugi T, Mizunuma K, et al. Occupational 
dimethylformamide exposure. 2. monomethylformamide excretion in urine after occupational dimethylformamide exposure. Int Arch Occup Environ Health 1992; 63: 455460.

16) Kimmerle G, Eben A. Metabolism studies of N,Ndimethylformamide. I. Studies in persons. Int Arch Arbeitsmed 1975; 34: 127-136.

17) Yonemoto J, Suzuki S. Relation of exposure to dimethylformamide vapor and metabolite methylformamide in urine of workers. Int Arch Occup
Environ Health 1980; 46: 159-165.

18) Mraz J, Nahova H. Percutaneous absorption of N,Ndimethylformamide in humans. Int Arch Occup Environ Health 1992; 64: 257-262.

19) Wrbitzky R, Angerer J. N,N-dimethylformamide influence of working conditions and skin permeation on the internal exposure of workers in synthetic textile production. Int Arch Occup Environ Health 1998; 71 : 309-316. 